\section{All Bad? Experiences of Aging Among LGBT Elders in South Africa}

The International Journal of Aging and Human Development 2019, Vol. 88(4) 405-42I

(C) The Author(s) 2019

Article reuse guidelines: sagepub.com/journals-permissions DOI: $10.1177 / 0091415019836929$

journals.sagepub.com/home/ahd

(SAGE

\author{
Finn Reygan ${ }^{1,2}$ (D) and \\ Neil Henderson ${ }^{2}$
}

\begin{abstract}
There is an almost complete dearth of research on the lives of lesbian, gay, bisexual, and transgender (LGBT) elders in South Africa. This study was a qualitative exploration through focus group discussions of the lived experiences of 22 LGBT people over 50 years of age in the Western Cape and Gauteng provinces of South Africa. Given high levels of poverty and inequality in South Africa, findings from a thematic analysis of participants' narratives foregrounded surprisingly strong themes of inclusion and belonging despite the structural challenges faced by many in South Africa. While narratives of marginalization and exclusion were present, these were juxtaposed with reports of belonging and inclusion in families, communities, through friendship networks, and in health care. Findings indicate that, while experiences of homophobia and transphobia are real among LGBT elders in South Africa, participants experience agency, support, and relatively high reported levels of social belonging as they age.
\end{abstract}

\title{
Keywords
}

LGBT, aging, South Africa, belonging, inclusion

\section{Introduction}

Literature on lesbian, gay, bisexual, and transgender (LGBT) older persons emerges from a range of contexts including the United States, the United Kingdom,

\footnotetext{
'Human Sciences Research Council, Pretoria, South Africa

${ }^{2}$ University of the Western Cape, Cape Town, South Africa

Corresponding Author:

Finn Reygan, Human Sciences Research Council, I34 Pretorius Street, Pretoria 000I, South Africa.

Email: FReygan@hsrc.ac.za
} 
Canada, Australia, and Ireland among others, and the focus of this literature is often on care needs. This research often paints a rather negative picture of depression, social isolation, and suicide (Almack, Seymour, \& Bellamy, 2010; FredriksenGoldsen et al., 2012; Stonewall Report, 2011). There is also a belief that some LGBT people go "back into the closet" particularly when they are placed in retirement homes (GLBTI Retirement Association Inc \& Curtin Health Innovation Research Institut, 2010). In contrast, Gay and Lesbian Equality Network (2011) in Ireland found that the majority of LGBT people spoke of arriving at a place of contentment, comfort, and happiness with self. Fredriksen-Goldsen et al. (2013) in the United States found that almost all of the LGBT people who participated in the study felt good about belonging to their communities. Furthermore, they argue that family members play a primary role in the support of their elders and that older LGBT people care for each other. In addition, resilience is developed through living their lives as they want to and participating in their communities. In a study, Fredriksen-Goldsen et al. (2013) postulate that income and employment together with focusing on successes rather than economic status can contribute to a better life.

There is a substantial and growing body of research on sexual orientation and gender identity (SOGI) in South Africa (and indeed across Southern Africa) across sectors, such as in primary and secondary education (Francis et al., 2018; Reygan, 2016), in health (Reygan \& Khan, 2019), and in terms of violence and access to justice (Meer, Lunau, Oberth, Daskilewicz, \& Müller, 2017) among others. However, this research rarely, if ever, considers the specific lived experiences of LGBT elders and instead foregrounds the lives of younger LGBT people. To date, the only published work specifically on older LGBT people in South Africa is by (Reygan \& Khan, 2019) and Henderson \& Almack (2016). As a result, this article is one of the first in South Africa and indeed across the continent to engage explicitly with the lived experiences of aging of older LGBT identified people. Its findings both confirm and contradict some of our pre-existing ideas not just about aging but also about SOGI life in general in South Africa.

South Africa has one of the most progressive constitutions in the world that is often seen as a beacon of inclusion and tolerance (Reygan, 2015). Embedded in the Constitution is the Bill of Rights that enumerates a range of protected categories such as age, gender, and sexual orientation. Section 9 of the Constitution mandates that neither the state nor any non-state actor may:

... unfairly discriminate directly or indirectly against anyone on one or more grounds, including race, gender, sex, pregnancy, marital status, ethnic or social origin, colour, sexual orientation, age, disability, religion, conscience, belief, culture, language and birth. (Republic of South Africa, 1996)

In South Africa, old age is usually defined as postretirement which is 60 years for women and 65 for men (Older Persons Act 13 of 2006, RSA 2006). In terms 
Table I. Focus Group Discussion Participant Demographics.

\begin{tabular}{|c|c|c|c|c|}
\hline Pseudonym & Race & Gender & LGBT Status & Area of origin \\
\hline \multicolumn{5}{|c|}{ Johannesburg mixed group (II) } \\
\hline Diane & Colored & Female & Lesbian & Cape Town \\
\hline Mercia & Colored & Female & Lesbian & Cape Town \\
\hline Evelyn & Colored & Female & Lesbian & Cape Town \\
\hline Candice & Colored & Female & Lesbian & Mbabane (SZL) \\
\hline Sharon & Colored & Female & Lesbian & Alexandra $(\mathrm{JHB})$ \\
\hline Maxwell & White & Male & Gay & Johannesburg \\
\hline Terrence & Colored & Male & Gay & Durban \\
\hline Yusuf & Colored & Male & Gay & Johannesburg \\
\hline Alicia & Colored & Female & Lesbian & Cape Town \\
\hline Beverly & Colored & Female & Lesbian & Cape Town \\
\hline Patricia & Mestiza Colombian & Female & Lesbian & Colombia \\
\hline \multicolumn{5}{|c|}{ Cape Town, Black gay group (4) } \\
\hline Vusi & Black & Male & Gay & Gugulethu \\
\hline Fikile & Black & Male & Gay & Gugulethu \\
\hline Radebe & Black & Male & Gay & Gugulethu \\
\hline Lungile & Black & Male & Gay & Gugulethu \\
\hline \multicolumn{5}{|c|}{ Cape Town transgender group (3) } \\
\hline Sammy & Colored & Male & Transgender & Woodstock \\
\hline Cindy & Colored & Male & Transgender & Mitchells Plain \\
\hline Jane & Colored & Male & Transgender & Cape Town \\
\hline \multicolumn{5}{|c|}{ Cape Town, colored gay and bisexual group (4) } \\
\hline Freddy & Colored & Male & Bisexual & Athlone \\
\hline Hash & Colored & Male & Gay & Retreat \\
\hline Mike & Colored & Male & Gay & Cape Town \\
\hline Vin & Colored & Male & Gay & Cape Town \\
\hline
\end{tabular}

Note. LGBT = lesbian, gay, bisexual and transgender.

of legislation on aging and the rights of older people, the Older Persons Act 13 of 2006 aims to:

... deal effectively with the plight of older persons by establishing a framework aimed at the empowerment and protection of older persons and at the promotion and maintenance of their status, rights, well-being, safety and security; and to provide for matters connected therewith. (Republic of South Africa, 2006)

However, as is often the case, South Africa tends to be policy rich and implementation poor as the country continues to grapple with the apartheid legacy in terms of inequality and unequal distribution of resources and opportunities. 
For example, barriers to accessing formal elder care include inequalities on the basis of race and class and a survey of 145 old-age homes found that $77 \%$ of residents in these homes were White, Afrikaans females (Perold, 2000). More broadly, issues of access and affordability are burning questions in a national context of great inequality given that South Africa is one of the most unequal countries in the world (Tregenna \& Tsela, 2012). South Africa has underresourced and unequal public health service delivery and medical aid schemes tend not to cover care that is administered beyond registered frail care facilities. Conversations around institutional care also neglect the practice of home-based care typical of the majority Black African population. South Africa also occupies a particular geopolitical space in that it is officially classed as an upper middle income country but in reality inhabits a space between the developed and developing countries (Nieman \& Fouché, 2016). For example, it participates in the BRICS grouping of developing nations (Brazil, Russia, India, China, and South Africa) and competes with Nigeria to be the leading economic powerhouse on the African continent despite its severe levels of national inequality.

We highlight very briefly these broader macronational realities as experiences of aging and elder care play out in a way very much determined by these realities, which are in turn grounded in broader African worldviews and experiences. For example, Makiwane (2011) interrogates family structures that enable or undermine the process of growing old well in South Africa and highlights that in many developing world contexts elders often live with their children, a reality determined both by cultural norms in relation to family and as a result of economic realities.

In short, the very limited literature on the lives of LGBT elders in South Africa foregrounds a number of possible avenues for future research. First among these is simply more information on the lived experiences of LGBT elders given the almost complete silence in the literature on this topic. Second, the experiences of LGBT elders both in terms of community belonging and in terms of access to health care are important, necessary next steps in elucidating the lives of older LGBT people in South Africa. As a result, the primary research question guiding this study was as follows: "What are the lived experiences of LGBT elders in South Africa?" A secondary research question was as follows: "What is the impact of the current social context in South Africa on the lives of LGBT elders?" So as to answer these questions, this exploratory study conducted focus group discussions (FGDs) with LGBT elders in two provinces in South Africa. The study design is outlined later followed by the presentation of findings, a final discussion of the implications of these findings including future policy and programming, and finally the limitations of the study and possible directions for future research. 


\section{Method}

\section{Research Design and Procedure}

This was an explorative, qualitative study, and Creswell (2014) suggests that qualitative research is about recognizing the meanings that participants hold about a problem. The study intended to explore and describe LGBT people's understanding of their experiences. Four focus groups were held in total: three in the Western Cape province that includes Cape Town and one in Gauteng province that includes Johannesburg. While individuals in a focus group usually take the lead in the discussion (Thomas, 2011), possibly due to their marginalization, some participants in this study were reluctant to take the lead and the facilitator in the Western Cape became more involved in getting the discussion going. Participants were identified through referrals from LGBT civil society organizations in the two provinces and were selected into the study on the basis of their age and identity. In terms of sampling criteria, participants had to be over 50 and identify as LGBT. However, over the 12 months that data collection took place, it was decided that LGBT persons close to 50 could also participate due to challenges with finding participants. This links to the importance of reaching saturation (Charmaz, 2006) where no new insights are revealed.

\section{FGD Guideline}

A FGD guideline should have well-thought out questions, primarily open-ended questions, allowing participants freedom to respond from a variety of viewpoints (De Vos, Strydom, Fouche, \& Delport, 2011). The FGD guideline began with asking participants to describe how they wished to be called in the group in terms of preferred name, gender pronoun, and so on. They were then asked to describe how they came out as an LGBT person and what the response of their families was. Furthermore, facilitators asked participants to draw an ecomap individually and separately during the focus groups for approximately 20 to 30 minutes so as to identify people who were part of their current network either in a supportive or nonsupportive capacity. After participants separately completed their ecomaps, the group reconvened and participants discussed their own ecomaps. This is a participatory learning and action technique (Bozalek \& Biersteker, 2010), and the aim was to get older LGBT people to reflect on who was involved in their lives and whether these people played a significant role in their lives. The rest of the FGD guideline focused on how participants were coping with health issues, had they planned for residential care, did they understand their legal options in terms of wills and hospital care, and had they planned end of life care? 


\section{Focus Group Process}

Recruitment issues have practical and budgetary implications (Kroll, Barbour, \& Harris, 2007). Participants were identified by the civil society organizations Triangle Project and Gender Dynamix in the Western Cape and through networking in Gauteng. Key informants within the LGBT community were asked to identify participants since organizations had few records of older LGBT clients. There were two meetings held in the community to explain the project to potential participants. These were organized by Triangle Project, an LGBT nongovernmental organization, and approximately 25 people attended the meetings. The focus groups convened at different community centers in the Western Cape and in a community center in Johannesburg in Gauteng. They met on a Saturday morning when participants were available to meet as some participants were still working. Participants were asked to give their informed consent to attend the focus groups and a total of 22 participants took part in the focus groups (see Table 1). The three focus groups in the Western Cape had 3-4 participants, whereas the focus group in Gauteng was larger and participants came from diverse communities. In terms of demographics, the Gauteng focus group consisted primarily of lesbian women, and the Western Cape focus groups were attended primarily by gay men, three transgender people, and one bisexual participant. Overall, ages across the focus groups ranged from 50 to 72 years.

Methodologically, smaller groups are preferable in focus groups, as this allows participants to relate intense experiences (De Vos et al., 2011) and most of the participants in the focus groups were from marginalized communities in terms of race, class, and SOGI. It required a year to complete the four focus groups, and there were challenges in identifying older LGBT people in the Western Cape because civil society organizations working in the LGBT sector tended not to have a strong focus on older LGBT people. As a result, meetings were called with LGBT and other community organizations to describe the study and request participation. Some participants did not arrive for the FGDs although transport was available and in some instances, venues were not always suitable for discussions. For example, at Grassy Park, the venue was next to a highway so people had to shout due to the noise level. Some gay men living in the townships could not attend as they were in a wheel-chair and the transport was not suitable. Despite these challenges, participants were generally engaged and responsive and there was good support from research assistants who attended the focus groups and recorded them using a digital recorder. The research assistants had attended a prior training workshop at Gender Dynamix to ensure that they were cognizant of appropriate language use with LGBT older people. 


\section{Data Analysis}

The focus groups were audio-recorded and transcribed verbatim and two transcribers were utilized, one in the Western Cape and one in Gauteng. There were challenges with this process as one of the transcribers had to be replaced due to time constraints. The transcriptions were then edited and analyzed by a data analyst who is an experienced researcher in Social Work at one of the authors' affiliated institutions. The data analyst was not part of the research team but assisted the authors to complete the research process within the grant timeframes. There was consensus on these themes which were then further analyzed by the authors so as to generate codes, develop further themes and sub-themes and link relevant quotes to each theme. In short, five people read through the data, which were the two transcribers, the data analyst, the first author, and the second author. Data from the Gauteng focus group were analyzed separately, as there were differences in how the questions were posed in the Gauteng province FGD.

\section{Ethics Approval}

The project was granted ethics approval by the National Research Foundation of South Africa and in every focus group, participants were informed about the project and gave their consent to participate. Thomas (2011) writes about implied consent where participants are given a clear explanation of opting out though e-mail, telephone, or personally though no participants in the study chose this option. Participants also signed a confidentiality binding form, anonymity was ensured during the data analysis phase as pseudonyms were given to each participant, and participants were debriefed after each session.

\section{Results}

Participants were not asked to talk specifically about positive and negative experiences of aging, but these became apparent in the course of the guided conversations. There were the expected stories of rejection, marginalization, and loneliness, and some of these are presented later as they reflect lived realities of LGBT people in general in South Africa. However what was surprising in this explorative study was the frequency of narratives of belonging, inclusion, care and support from the families, communities, friendship networks, and the health-care providers of participants. These experiences of belonging and social inclusion are presented later in four broad thematic areas: family support, friendship networks, community support, and health-care access. 


\section{Family Support}

All participants in the study identified at least one family member who provided them with care and support, including partners and children from previous, opposite sex marriages:

My ex-wife and my children, they are my neighbours, they have accepted me, they still support me. I help them and I'm still there for them. (Freddy: Colored, Male, Bisexual)

South Africa has some of the highest rates of HIV in the world and the world's largest per capita roll out of public antiretroviral treatment. While stigma continues to exist in relation to HIV/AIDS, many public campaigns and public health efforts to have people tested and treated have led to a change in social attitudes. This was reflected in family support for study participants, including in the context of a HIV diagnosis:

He [doctor] told me I was HIV positive and I said thank you. The first thing I did was call my kids, called my cousin in Joburg and I told them this and my sister whom I stay with, I told her I have this. They never threw me away and I still get the support from them even up until now as far as I am taking my medication. Even when I am going out for a jol [to go out to socialise and party] by eight o'clock I know I must take my stuff. (Vusi: Black, Male, Gay)

While systemic violence, poverty, and substance abuse have eroded family and kinship networks in South Africa in recent years, the concept of African kinship networks as central to the individual's experience was apparent:

My story or support would be my family because they are my priority and that's why I put them first before anyone and everyone else. In the family that I have now at the moment are three sisters, with three great brothers-in-law, wonderful nieces and nephews. I've even got one nephew that's living with me but he has been with us since he was a baby: family first! (Patricia: Mestiza, Female, Lesbian)

The patriarchal nature of South African society was apparent in the narratives of participants. South African gender norms continue to construct "men" as family providers and heads of household which contrasts with lived realities in which over half of families are single headed households, led by women. While traditional gender norms continue to perpetuate high levels of gender-based violence and femicide in South Africa, such gender constructs are not always exclusionary of LGBT people. Participants in the study repeatedly flagged the social roles that they took on in both their families and 
communities that provided a sense of belonging, albeit in traditionally gendered ways:

My sister is a very positive person. Even if I called her or just don't have airtime [for a mobile phone] sometimes she will call me immediately and then we will just talk, talk, talk and she does respect me a lot. She doesn't call me by my name, she will call me boetie ['brother' in Afrikaans] all the time because in my culture if you're a man-it doesn't matter you gay or what-that respect must be there. (Fikile: Black, Male, Gay)

\section{Friendship Networks}

The global literature on LGBT kinship highlights the important role of friendship as a key support for sexual and gender minorities, including older LGBT people. Worldviews such as Ubuntu that characterize a sense of collective community belonging and inclusion in South Africa and across the region, also emphasize the centrality of mutual interdependence among community members. Especially in contexts characterized by high levels of inequality, poverty, and resulting precariousness including the real possibility of homelessness, the sense of the collective is an important psychological buffer and material support system in the face of high levels of unemployment and poor quality, public service delivery:

I've got a friend who is older than me. He is about 65 and has been my friend for the last five years. He was just about turning 60 and he was waiting for his salary. He had no job and I gave him a bit of support and through being on the street together we became friends. Today he is my support and I have met his friends and now we are a nice group supporting one another: so that's the snowball effect. (Freddy: Colored, Male, Bisexual)

In the postapartheid context of ongoing economic marginalization and lack of access to resources, especially for the majority Black African population, friendship networks including for LGBT elders often function as material support in terms of access to food, shelter, and communication, such as with airtime for mobile phones:

I have a lover and if I'm hungry like last Thursday or Wednesday, I asked for airtime from him and he said: "You know what? I'm going to send you airtime this month." This is because it was my birthday and he sent me money in advance because it was my birthday. (Fekile: Black, Male, Gay) 
The loneliness that can characterize the lives of older LGBT people appeared substantially mitigated for participants through strong family and friendship networks. While narratives of isolation and loneliness would have been the expected outcome of aging in supposedly homophobic and transphobic contexts, these narratives were largely absent. In their place were repeated references to the caring and support role of friends during times of illness, increased vulnerability and at particular moments in the year:

I went for a major operation but my friends were around me every day. My house was full of people, cleaning my place and cooking food for me: It was nice actually having everybody around me. (Vin: Colored, Male, Gay)

Since I met my new group of LGB [lesbian, gay and bisexual] friends they have been a great support for me in the last few months and at Christmas I wasn't alone as I had a whole big family. (Freddy: Colored, Male, Bisexual)

\section{Community Support}

Narratives of alienation and homophobia were present in participants' reports:

It's not about the gay community, it is heterosexual people, when they are in need and they would call: "Could you assist me in this?" Because they know you've got channels, they are using you. I feel annoyed, I feel angry, and I feel like I'm being used, not by my own community, but by other people, by the heterosexual community. (Radebe: Black, Male, Gay)

Nevertheless, the narratives of participants generally foregrounded experiences of community belonging, inclusion and support:

I have a good relationship with people in our communities and funny enough it's a whole lot of young people who often come sit in the office just to chat and ask me to assist them with certain things: They don't want to leave! With our vulnerable groups programme, we actually go out and look after people so I've got a good band of people who go out with me with me assisting old people. (Hash: Colored, Male, Gay)

I have a strong structure and I am involved in community meetings. They listen to me and my advice and all that especially now that I'm working with a crime related programme that is based in the community. I am also working with children and I have established a street sports team and also I'm involved in the environmental stuff. (Radebe: Black, Male, Gay) 
While the support of friends in particular is unsurprising given that friendship networks often function as de facto families for queer people globally, participants in the study also spoke with conviction about the support they received from the larger community. This level of care and support was often premised on caring roles that participants themselves took on as elders in the broader community, which is a role that typifies aging in broadly African contexts. This dynamic speaks to understandings of family and kinship in both South Africa and across the region and is engaged with more in-depth in the discussion. In short, one of the ways in which participants created a sense of belonging was through taking on the role of caregiver for others. As is the case with elder abuse more generally in South Africa, such as older people being manipulated for their small monthly state pension, participants indicated that they sometimes experienced being taken for granted and used by the people they cared for. Nevertheless, participants cared for people in the broader community through giving advice, advocacy support, as well as practical support such as food and transport for the older adults:

I would invite people to my home and cook, if its winter I would make soup. People will come with their little bakkies [vans] and say: "I heard from the neighbour you make nice soup, can I have some?" So those are the types of support and when I am ill, like I was ill for the whole week, I don't know how many people knocked on my door: "What can I help you with?" (Vusi: Black, Male, Gay)

This worldview of mutual care, support, and interdependence, even in the face of rampant crime and violence, was something that participants experienced as "the way things should be" and "natural":

It comes from inside: You support everybody in a way that you don't realise that you are supporting them. It's just something that comes naturally and it comes with your values. (Vusi: Black, Male, Gay)

My neighbours, mostly elderly people: I'm there for them and recently I have taken one to the hospital. Once a month I take the other neighbour to the hospital before I go to work because she goes for a check-up. So the one came to knock on my door at 3 a.m. so I even took her to the hospital but I have been like that all the time. I like to give to the aged people because they haven't got anybody else to take care of them. (Vin: Colored, Male, Gay)

\section{Health-care Access}

Access to quality health care is a challenge for the majority of South Africans who live without medical insurance. This leads to a situation in which most 
people rely on a generally ineffective and underresourced public health system. There is a strong narrative of health-care provider homophobia and transphobia in South Africa, which functions as a barrier to health care for LGBT people. However, while participants in the study were not in denial of these realities ("Government hospitals and stuff are terrible [but] fortunately I am on medical aid." Vin: Colored, Male, Gay), they also were generally positive about the levels of support and inclusion they received from the public health system:

The clinic that I go to, the health for men clinic, they are very supportive, even from the reception through to the nurses the doctors: They are very supportive. (Fikile: Black, Male, Gay)

I wanted to just check my HIV status and then I went to a local clinic and they assisted me, but they were quite comfortable and they were actually very broadminded and did everything with confidentiality. (Freddy: Colored, Male, Bisexual)

The rights-based culture in South Africa of the postapartheid context leads to a situation in which people are often aware that they may have rights in a particular area and realize that they need to be "empowered":

Yes, they do discriminate but if you are empowered enough and you can raise your voice and then they will listen to you because they know that this is not a person that I can mess around with. (Sammy: Colored, Male, Transgender)

Given constitutional and legislative provisions in relation to SOGI rights, there is a strong sentiment among the LGBT population generally and LGBT elders in this study that belonging and inclusion are a fundamental right:

I never experienced any discrimination. Two weeks ago I was at Groote Schuur [hospital in Cape Town] and the people that visited me were openly gay coming with flowers and water and juices and all that. The nurses said, "You've got lovely friends. I never experienced discrimination, especially in the government hospitals and clinics. I think we need to look at the issue of democracy and that people are more educated when it comes to the LGBT community." (Vusi: Black, Male, Gay)

\section{Discussion}

This study, one of the first in South Africa specifically on experiences of aging among LGBT older people, expected to unearth narratives of loneliness, abuse, poverty, violence, and exclusion. Such narratives would reflect the realities of many people in a country considered to be one of the most unequal in the world as indicated by its Gini coefficient, which is a statistical measure of economic 
inequality related to income distribution, characterized by extremely high levels of violence, including gender-based violence and homophobic and transphobic violence. Nevertheless, the narratives of participants presented in this study, while cognizant of and impacted by the prevailing social, cultural, and economic challenges, also tell us something else about aging as a queer person in South Africa.

While tentative, these lessons include the influence of African cultural beliefs and norms, including concepts such as Ubuntu, belonging, and interdependence. While individualism in the context of advanced capitalism is pervasive in the Global North, a philosophy of communitarianism remains embedded in the social and cultural norms in South Africa and across Southern Africa. As a result, there is an ongoing expectation that young people care for older community members and that older people have important community roles, including as care givers to others. While this philosophy has been eroded in recent years by rampant violence, poverty, and inequality, it nevertheless remains as a cornerstone of life in South Africa and emerges in the reports of LGBT elders in this study.

Another key lesson emerging from this study is the resilience and agency among LGBT people and especially among older LGBT people who would have lived through turbulent times, including the transition out of apartheid. While some level of alienation and exclusion from heterosexist society is evident, participants' narratives overwhelmingly point toward experiences of struggle in the broader context of poverty and structural inequality on the basis of class and race. This resilience points toward an understanding of the ways in which the struggle for LGBT equality is embedded in the struggles of the broader Black and Colored communities in which participants live. As a result, the participation in and contribution to the broader, often township, communities in which they live functions to offer participants a level of belonging and inclusion.

South Africa is a rich country in comparison to its neighbors in Southern Africa and across the continent. However, the tax base remains small, and the challenge of corruption often means that state funds fail to reach intended communities. The results of this corruption and mismanagement are an underperforming primary and secondary school system and a broken public healthcare system. In this context of compromised state support and poor service provision, the importance of relying on family, friends, and community increases. This is apparent in the lives of the LGBT elders in this study who found and offered support, both in the LGBT community and the broader community, as a buffer to a state that often fails to care for its most marginalized and vulnerable communities. Recent survey data (Sutherland, Roberts, Gabriel, Struwig, \& Gordon, 2016) also point to an ongoing shift in broad societal attitudes in South Africa in relation to SOGI. As a result, the evidence base is beginning to challenge the notion of "African homophobia" and points rather in the direction of a more nuanced understanding of the ways in which 
African societies engage with issues of diversity, including the confluence of aging with sexual and gender diversity.

Within this context of shifting social attitudes and the challenges of a developing and unequal economy, there are implications for policy and programming emerging from the findings in this study. While the constitutional and legislative mandate in South Africa is progressive and inclusive in terms of SOGI, this does not necessarily trickle down into inclusive policy and programming and national government departments do not always name LGBT populations in policy and programming. In this context, LGBT elders, as a subsection of the broader LGBT population, are almost entirely invisible in policies and programmatic roll out even among national departments whose mandate should include SOGI, such as with social development and health. Therefore, a key recommendation emerging from this study is the completion of a national needs analysis of LGBT elders, particularly in relation to access to health care, and the revision of both policy and interventions on the ground so as to be inclusive of LGBT elders in particular.

\section{Limitations and Future Directions}

The study presents a number of limitations, primarily the limited size and nature of the sample. The sample includes primarily gay men and lesbian women with only one bisexual participant and three transgender participants. As a result, the perspectives of transgender South Africans are not equally represented in this study. Furthermore, in comparison with national demographics, there is an overrepresentation of Colored (a multiracial ethnic identity in South Africa) participants in comparison with the majority Black population, White, or Indian participants. The sample was also drawn from just two of South Africa's nine provinces, which were the Western Cape, which includes the city of Cape Town, and Gauteng, which includes Johannesburg. Finally, while the sample was mixed in terms of gender, the voices presented in this study are primarily male voices and so future analysis and future research require a deeper analysis by gender.

These sample characteristics result from a difficulty in accessing a broad cross section of LGBT elders in South Africa. The authors engaged their own networks in LGBT civil society to access participants and found that few LGBT civil society organizations keep the contact details of LGBT elders. This situation foregrounds the additional invisibility of an older cohort of LGBT people in South Africa and the implications this has for researching older sexual and gender minority populations. As a result, the demographics of the sample have presumably contributed to the type of narratives reported in this study. Future research could fruitfully engage more comprehensively with the experience of a 
majority Black sample and in greater depth with the experience of transgender elders from a wider range of provinces across the country.

\section{Declaration of Conflicting Interests}

The authors declared no potential conflicts of interest with respect to the research, authorship, and/or publication of this article

\section{Funding}

The authors disclosed receipt of the following financial support for the research, authorship, and/or publication of this article: This work was supported by National Research Foundation of South Africa (Project \# BBB0522168520/BB0500007, to N. H.).

\section{ORCID iD}

Finn Reygan (D) http://orcid.org/0000-0002-8414-2975

\section{References}

Almack, K., Seymour, J., \& Bellamy, G. (2010). Exploring the impact of sexual orientation on experiences and concerns about end of life care (EOLC) and on bereavement for lesbian, gay and bisexual elders. Sociology, 44(5), 908-924.

Bozalek, V., \& Bierseker, L. (2010). Exploring power and privilege using participatory learning and action techniques. Social Work Education, 29(5), 551-572.

Charmaz, K. (2006). Constructing grounded theory: A practical guide through qualitative analysis. London, England: SAGE.

Creswell, J. W. (2014). Research design. Thousand Oaks, CA: Sage.

De Vos, A. S., Strydom, H., Fouche, C. B., \& Delport, C. S. L. (2011). Research at grassroots. Pretoria, South Africa: Van Schaik.

Francis, D. A., Reygan, F., Brown, A., Dlamini, B., McAllister, J., Nogela, L., ... Thani, G. T. (2018). A Five Country Study of Gender and Sexuality Diversity and Schooling in Southern Africa. Africa Education Review, 1-21.

Fredriksen-Goldsen, K. I., Emlet, C. A., Kim, H. J., Muraco, A., Erosheva, E. A., Goldsen, J., \& Hoy-Ellis, C. P. (2013). The physical and mental health of lesbian, gay male, and bisexual (LGB) older adults: The role of key health indicators and risk and protective factors. The Gerontologist, 53, 664-675.

Fredriksen-Goldsen, K. I., Kim, H.-J., Emlet, C. A., Muraco, A., Erosheva, E. E., HoyEllis, C. P.,... Petry, H. (2012). The aging and health report: Disparities and resilience among lesbian, gay, bisexual and transgender older adults. Seattle, WA: Institute for Multigenerational Health.

Gay and Lesbian Equality Network. (2011). Visible lives: Identifying the experiences and needs of older lesbian, gay, bisexual and transgender people in Ireland. Dublin: Author.

GLBTI Retirement Association Inc \& Curtin Health Innovation Research Institute. (2010). We don't have any of those people here: Retirement accommodation and aged care issues for non-heterosexual populations. Perth, Australia: Curtin University. 
Henderson, N. J., \& Almack, K. (2016). Lesbian, gay, bisexual and transgender ageing and care: A literature study. Journal of Social Work, 52(2), 267-279.

Kroll, T., Barbour, R., \& Harris, J. (2007). Using focus groups in disability research. Qualitative Health Research, 17(5), 690-698.

Makiwane, M. (2011). Intergenerational relations in Africa with a focus on South Africa (p. 6). Retrieved from UN/POP/EGM-AYD/2011/09.

Meer, T., Lunau, M., Oberth, G., Daskilewicz, K., \& Müller, A. (2017). Lesbian, gay, bisexual, transgender and intersex human rights in Southern Africa: A contemporary literature review 2012-2016. Johannesburg, South Africa: HIVOS.

Nieman, G., \& Fouché, K. (2016). Developing a regulatory framework for the financial, management performance and social reporting systems for co-operatives in developing countries: A case study of South Africa. Acta Commercii, 16(1), 1-7.

Perold, A. (2000). The composition of old age homes in South Africa in relation to the residents and nursing personnel. Curationis, 23(1), 87-94.

Reygan, F. \& Khan, J. (2019) Sexual and gender diversity, ageing and elder care in South Africa: voices and realities. In: A. King, K. Almack \& R. Jones (Eds), Intersections of ageing, gender and sexualities: Multidisciplinary perspectives. Chap. 11, Policy Press: Bristol.

Reygan, F. (2015) Black lesbian (non)representation in 'gay' media in Cape Town: Constructing a globalized white, male, affluent, gay consumer. African Identities, 14(1), 85-98.

Reygan, F. (2016). Teaching about sexual diversity and challenging homophobia/transphobia in the South African school system. In S. Russell \& S. Horne (eds). Sexual orientation, gender identity, and schooling: The nexus of research practice and policy. Oxford: Oxford University Press.

Republic of South Africa. (1996). Bill of Rights. Government Printer: Pretoria.

Republic of South Africa. (2006). Older Persons Act 13 of 2006. Government Printers: Pretoria.

Stonewall Report. (2011). LGB people living in later life. Retrieved from https://www. stonewall.org.uk/sites/default/files/LGB_people_in_Later_Life_2011_.pdf

Sutherland, C., Roberts, B., Gabriel, N., Struwig, J., \& Gordon, S. (2016). Progressive prudes: A survey of attitudes towards homosexuality \& gender non-conformity in South Africa. Johannesburg, South Africa: The Other Foundation.

Thomas, G. (2011). How to do your research project. London, England: Sage.

Tregenna, F., \& Tsela, M. (2012). Inequality in South Africa: The distribution of income, expenditure and earnings. Development Southern Africa, 29(1), 35-61.

\section{Author Biographies}

Finn Reygan is Chief Research Specialist at the Human Sciences Research Council (HSRC), extraordinary associate professor in the Department of Educational Psychology at the University of the Western Cape, and Visiting Senior Research Fellow at the Wits Centre for Diversity Studies (WiCDS) at the University of the Witwatersrand. He publishses in the field of gender and sexualities and sits on a number of committees in South Africa focused on diversity and transformation at a systems level. 
Neil Henderson is a lecturer in the Deparment of Social Work at the University of the Western Cape. In 2014 he was given a fellowship at the Sue Ryder Centre at Nottingham University to research LGBT ageing and care which led to a three year research project with the National Research Foundation on LGBT ageing and care in South Africa. 